Bryn Mawr College

Scholarship, Research, and Creative Work at Bryn Mawr

College

Psychology Faculty Research and Scholarship

Psychology

2011

\title{
Vocabulary Development in Greek Children: A Cross-Linguistic Comparison Using the Language Development Survey
}

Christina F. Papaeliou

Leslie Rescorla

Bryn Mawr College, lrescorl@brynmawr.edu

Let us know how access to this document benefits you.

Follow this and additional works at: http://repository.brynmawr.edu/psych_pubs

Part of the Psychology Commons

\section{Custom Citation}

Papaeliou, Christina F., and Leslie A. Rescorla. "Vocabulary Development in Greek Children: A Cross-Linguistic Comparison Using the Language Development Survey." Journal of Child Language 38, no. 4 (2011): 861-887, doi: 10.1017/S030500091000053X.

This paper is posted at Scholarship, Research, and Creative Work at Bryn Mawr College. http://repository.brynmawr.edu/psych_pubs/8

For more information, please contact repository@brynmawr.edu. 
7. Child Lang. 38 (201 I), 86I-887. (c) Cambridge University Press $201 \mathrm{I}$ doi:10.1017/So30500091000053X

\title{
Vocabulary development in Greek children: a cross-linguistic comparison using the Language Development Survey*
}

\author{
CHRISTINA F. PAPAELIOU \\ Department of Preschool Education and of Educational Planning, \\ University of the Aegean, Greece
}

AND

LESLIE A. RESCORLA

Department of Psychology, Bryn Mawr College, Bryn Mawr, Pa., USA

(Received I I March 2009 -Revised 30 November 2009-Accepted I 5 August 2010-

First published online I 7 May 201 I)

\section{A B S TRACT}

This study investigated vocabulary size and vocabulary composition in Greek children aged I ; 6 to 2; I I using a Greek adaptation of Rescorla's Language Development Survey (LDS; Rescorla, I989). Participants were 273 toddlers coming from monolingual Greek-speaking families. Greek LDS data were compared with US LDS data obtained from the instrument's normative sample (Achenbach \& Rescorla, 2000). Vocabulary size increased markedly with age, but Greek toddlers appeared to get off to a slower start in early word learning than US children. The correlation between percentage word use scores in Greek and US samples was moderate in size, indicating considerable overlap but some differences. Common nouns were the largest category among the fifty most frequent words in both samples. Numbers of adjectives and verbs were comparable across languages, but people and closedclass words were more numerous in the Greek sample. Finally, Greek late talkers showed similar patterns of vocabulary composition to those observed in typically developing Greek children.

\section{INTRODUCTION}

Cross-linguistic child language research was established by the pioneering studies of Dan Slobin and his colleagues (Slobin, I 992), who focused on the

[*] Address for correspondence: Christina Papaeliou, Miltiadou 39, P. Faliro, I $75-63$, Greece. e-mail: papailiou@rhodes.aegean.gr 
acquisition of early grammar using analyses of transcripts of spontaneous language collected in relatively small samples of children. In the past two decades, a large body of research has also examined cross-linguistic variation in early lexical development (Dale \& Goodman, 2005). In contrast to the methodology used in cross-linguistic grammar studies, cross-linguistic lexical studies have typically used analyses of parent reports of vocabulary collected for relatively large samples. Most of these studies have used a version of the MacArthur-Bates Communicative Development Inventory (CDI) (Fenson et al., I993), which has been translated into many languages. Contributors to this body of research have recognized that to make systematic quantitative comparisons across countries in vocabulary development, and thereby determine cross-linguistic commonalities and differences, it is necessary to conduct the same kinds of analyses with data collected using the same instrument (Dale \& Goodman, 2005).

The methodology for systematic cross-linguistic analysis of lexical development was recently articulated by Bleses et al. (2008a), who were able to find eighteen CDI studies that met their inclusionary criteria of: (i) using an adaptation of the CDI 'as close as possible to the original American English CDI-reports'; (ii) collecting data in a 'population-based' sample (i.e. not a special population, such as bilingual children); and (iii) publication of results of 'basic analyses of lexical development'. As Bleses et al. (2008a) noted, by using the 'American CDI-instrument that has been adapted to numerous languages' one can carry out 'controlled cross-linguistic comparisons between many different languages, as it is possible to compare parallel measures sampled using equivalent procedures across studies' (p. 62 I). It should be noted that this paradigm differs from earlier approaches to studying lexical acquisition, such as obtaining language diaries for a small number of children in order to do qualitative case studies of early vocabularies (Benedict, I979; Dromi, I987; Leopold, I939; Nelson, i 973).

In the current study, we present a cross-linguistic comparison of Greek and US lexical development based on parents' reports on the Language Development Survey (LDS; Rescorla, I 989; Rescorla \& Achenbach, 2002), a vocabulary checklist developed in the r 980 s to be used as a screening tool for identifying language delay in toddlers. The LDS consists of 3 Io words arranged into fourteen semantic categories and assesses spontaneous word production in children aged I; 6 to 2 ; I I. Like the 680-word CDI: Words and Sentences (Fenson et al., I993), the LDS has very strong test-retest reliability and good concurrent validity with various standardized instruments (Rescorla, I989; Rescorla \& Alley, 200I). Its sensitivity and specificity for the identification of toddlers with expressive language delays has also been well documented (Rescorla, I989; Rescorla \& Alley, 200 I). 
Although the LDS has half as many words as the CDI, the two instruments yield comparable results in terms of relative progress in vocabulary development, as indicated by a correlation of 0.95 between total vocabulary score on the LDS and the CDI, and a range of 0.84 to 0.94 across comparable semantic categories (Rescorla, Ratner, Jusczyk \& Jusczyk, 2005).

The LDS has been translated into about twenty languages, but only a few studies reporting data for languages other than English have been published to date (Junker \& Stockman, 2002; Patterson, I 998). To our knowledge, no systematic large-sample comparison of lexical development in Greek children with that of US children has been published, whether using the CDI or the LDS. Before detailing the goals of our study, we will first discuss the process of adapting a vocabulary checklist for use in other languages, then summarize the major findings that have been reported in cross-linguistic comparisons of lexical development using the CDI, and finally discuss some important characteristics of Greek.

\section{Translating and adapting a vocabulary checklist}

Adaptations of the CDI, as well as those of the LDS, have generally retained the category structure and content of the US English checklist, but they have necessarily adapted some of the vocabulary items to local cultural and linguistic conditions, as described by Bleses et al. (2008b). Even in countries where the same language is spoken and the cultures are quite similar, such as the UK and the US, some substitution of words is usually necessary, such as nappy for diaper and pushchair for stroller (Hamilton, Plunkett \& Shafer, 2000). Food words (e.g. 'cereal', 'hamburger') often require the most revision, because of diet differences across countries. Replacement of inappropriate food items is the most obvious example of the kinds of cultural and linguistic adaptations that need to be made, but items in other semantic categories may also need adaptation, depending on the language and cultural context involved. For example, 'mommy', 'daddy' and 'baby' are words usually retained in any translation. However, different words may be used for 'aunt' and 'uncle' in some languages depending on whether they are on the mother's or the father's side of the family (e.g. in Danish and Bulgarian). A word such as 'church' may be common in the experience of children in Western countries, but not in Asian or Middle Eastern countries, and words such as 'snow' and 'mitten' are much less applicable in warm climates than in cold climates.

Thus, obtaining a good adaptation of a vocabulary checklist involves retaining all words from the original that appear suitable for the local culture and replacing words that are not suitable with words in the same semantic category that are more relevant to the young child's experience. 
Once a translation is obtained, it is desirable to then obtain a backtranslation in English, so that any ambiguities or errors in translation can be addressed.

\section{Cross-linguistic CDI findings}

Dale and Goodman (2005) and Bleses et al. (2008a) have provided good summaries of cross-linguistic findings with the CDI. Major commonalities found in these studies include: (a) that children in every country vary widely in their rate of lexical acquisition, but that lexicons generally get larger with age, with acquisition accelerating from I; 0 to $2 ; 0$; (b) that girls tend to have larger reported vocabularies than boys; (c) that the lexicon comprehended typically exceeds the lexicon produced in the early months of language development; and (d) that expressive vocabulary progress is associated with progress in grammatical development. An interesting additional finding in three studies using the CDI in English indicated that children from the UK, Australia and New Zealand (Bavin et al., 2008; Hamilton et al., 2000; Reese \& Read, 2000) had smaller reported vocabularies than US children early in the acquisition period.

Wide individual differences in rate of vocabulary development during the second year of life are well documented. Some children are reported to produce little or no meaningful speech before I; 4, whereas others display expressive vocabularies of more than 300 words. Studies using the CDI-WS and the LDS in English demonstrate that at 2; o the vocabulary of the top го\% of children is almost nine times larger than the vocabulary of the bottom I0\% of children (Bates et al., I994; Rescorla \& Achenbach, 2002). Individual variation in early vocabulary has also been reported among children acquiring Spanish (Bornstein, Cote, Maital, Painter, Park \& Pascual, 2004; Jackson-Maldonado, Thal, Marchman, Bates \& Gutierrez-Clellen, r 993), Italian (Camaioni \& Longobardi, I 995 ; Caselli et al., I 995), Hebrew (Maital, Dromi, Sagi \& Bornstein, 2000) and Japanese (Tamis-LeMonda, Bornstein, Cyphers, Toda \& Ogino, I 992). Gender differences in early lexical development have also been widely reported (Rescorla, I989; Rescorla \& Achenbach, 2002; Fenson, Dale, Reznick, Bates, Thal \& Phethick, I 994), with girls typically having somewhat larger reported vocabularies than boys.

With respect to the composition of early lexicons, data from languages such as English, Hebrew and Italian (Benedict, I979; Caselli et al., I995; Dromi, I 987; Fenson et al., I 994; Rescorla, Alley \& Book, 200 I) reveal that early lexicons contain words from a variety of different semantic classes. For example, Rescorla et al. (200I) reported that the thirty-eight words present in the lexicons of at least $80 \%$ of their sample at 2 ; 0 to $2 ; 2$ included animal names ('dog', 'cat', 'bird'), foods ('juice', 'banana', 'cookie', 'apple'), toys ('ball', 'book'), clothes ('shoes', 'socks'), household items ('spoon', 'bed', 
'cup', 'key’), people ('mommy', 'daddy', 'baby') and social words ('no', 'byebye', 'hi', 'yes', 'thank you', 'please'). In addition, many of these early words seem to be among those most likely to be first acquired by late talkers (Rescorla et al., 200 I).

Bornstein et al. (2004), who collected data in seven countries using an early version of the CDI, reported that nouns predominated in early vocabularies in the early stages of acquisition in all seven countries. Bornstein et al. (2004) also noted that the relative preponderance of nouns relative to verbs, adjectives and closed-class words varied with vocabulary size, with nouns have the greatest predominance from 5 I to $\mathrm{I} O 0$ and Io $\mathrm{I}$ to 200 words. However, countries differed somewhat in non-noun word classes. For example, in Korean, verbs were more common than adjectives, but this was not the case in French, Belgian and Dutch. In the smallest lexicons (o to 50 words), nouns were more frequent than adjectives and closed-class words, but not more common than verbs.

Additional studies have indicated a greater predominance of nouns in early vocabularies for Spanish (Jackson-Maldonado et al., i 993), Hebrew (Maital et al., 2000), French (Bassano, 2000), German (Kauschke \& Hofmeister, 2002) and Italian (Caselli et al., I995). Also consistent with Bornstein et al. (2004), D’Odorico, Carubbi, Salerni \& Calvo (2001) found that noun predominance varied with vocabulary size and that there were marked individual differences in noun predominance. In contrast, there is some evidence that children learning Mandarin, Korean and Dutch do not show a strong predominance of nouns in their early vocabularies (Tardif, r 996 ; Tomasello \& Merriman, r 995). For example, Choi and Gopnik ( I 995) reported that nouns were more common than verbs in 50-word lexicons for nine Korean children, but verbs were more common than in children acquiring English. In general, however, cross-linguistic studies using vocabulary checklists and controlling for a variety of methodological and sociodemographic factors have found that even Korean and Dutch children acquire more nouns than verbs and learn object words faster than action words, just as English-speaking toddlers do ( $\mathrm{Au}$, Dapretto \& Song, I994; Bornstein et al., 2004).

Word acquisition tends to be slow in the first few months of lexical development, averaging about one or two words per month. However, towards the end of the one-word stage, the rate of vocabulary growth tends to accelerate markedly. Goldfield and Reznick (r990) found that the 'vocabulary spurt' characterizes children who concentrate their early linguistic efforts on learning names for things. On the other hand, some children's lexicons are more evenly distributed across nouns, verbs, modifiers, pronouns and other word classes, and their lexical growth is slower. The vocabulary spurt with a 'noun bias' has been observed in German-, Italian- and Japanese-speaking children (D’Odorico et al., 200 I ; 
Kauschke \& Hofmeister, 2002; Ogura, Dale, Yamashita, Murase \& Mahieu, 2006). On the other hand, Gopnik and Choi (I995), who reported that Korean-speaking children did not show a strong noun predominance in their early vocabularies, also reported a vocabulary spurt later than that for English-speaking children.

In summary, although some strong commonalities have been found in cross-linguistic lexical development using the CDI, some differences across cultures have also been found (Dale \& Goodman, 2005). However, because studies have varied in the kinds of statistical analyses used and in the types of findings reported (Bleses et al., 2008a), it has been difficult to draw definitive conclusions from existing cross-linguistic studies of lexical development. Additionally, it is important to see whether the commonalities observed with the CDI are also found using a different vocabulary checklist. Finally, it is beneficial to extend cross-linguistic lexical analysis to additional languages not heretofore studied using this methodology. To this end, the present study examined vocabulary development in Greek-speaking toddlers aged I ; 6 to 2 ; I in comparison with English-speaking toddlers.

\section{Characteristics of Greek}

Greek differs from English in many aspects of morphosyntactic structure. First, Greek is a 'pro-drop' language (like Spanish, Chinese and Italian), meaning that pronoun subjects can be omitted in free-standing declarative sentences and only tend to be used when they provide new or emphatic information. In contrast, English requires pronoun subjects in free-standing declarative sentences (even in contexts such as $I t$ is raining).

Verbs are more often the first element in sentences children hear in Greek than in English. Verbs also constitute a higher proportion of the content words that Greek children hear, compared to English-speaking children (Mackridge, I985; Stephany, r 997). Compared to English, Greek nouns have a richer inflectional system, with two numbers (singular and plural), three genders (masculine, feminine and neutral) and four cases (nominative, accusative, genitive and vocative). However, most nouns appear with only two different case forms in each of the two numbers (singular and plural), i.e. one form for nominative, accusative and vocative and one form for genitive. Nominative and accusative are the most frequently occurring cases. Finally, Greek exhibits a wide variety of diminutives which are highly frequent in child-directed speech (Thomadaki \& Stephany, 2007).

Most existing studies of Greek language development focus mainly on the acquisition of grammatical knowledge (e.g. Natsopoulos \& Xeromeritou, I 989; Philippaki-Warburton \& Spyropoulos, 2004; Stephany, I 997) and are hence peripheral to the current study. Most existing studies of Greek lexical 
development have been very small-scale case studies. For example, Karousou and her colleagues (Karousou, Kati \& Stambouliadou, 2008), who studied two Greek children from $0 ; 8$ to $2 ; 0$, noted that proto-words emerged by $\circ ; 8$, relevance to the situation of use emerged by 0.9 , and conventionality began to emerge in the first half of the second year. Kotsakidis (2003), who examined four Greek children, noted that the vocabulary spurt appeared later than has been reported for children learning English (i.e. later than I ; 8), but that Greek children demonstrated a spurt in verbs and function words earlier than has been reported for other languages. Christofidou and Stephany (2003) observed that the two children they studied (aged I ; 9 ) produced verbal lemmas in $4 . \mathrm{I} \%$ of their utterances, while the corresponding percentage in their input was $6 \cdot 3 \%$. In addition, Thomadaki and Stephany (2007), who studied one child, showed that $25 \%$ of the total number of nouns over the period from $\mathrm{I} ; 8$ to 3 ; 0 were diminutives. Finally, Petinou and Okalidou (2006) compared seven Cypriot-Greek children identified as late talkers with seven aged-matched typically developing counterparts at the ages of $2 ; 6,2 ; 9$ and $3 ; 0$. Although the study focused on the phonetic skills of the participants, data were also reported on expressive vocabulary assessed using a 600-word vocabulary list adapted from the CDI. Expressive vocabulary in the late talker group ranged from 39 to $5_{5} 0$ words $(M=83, S D=40)$, while in the control group ranged from 290 to 500 words $(M=396, S D=73)$.

In sum, because Greek has more variable word order and more inflection of verbs, nouns and closed-class words than English, it is possible that Greek children might show some differences in rate of acquisition and in word frequencies relative to US children when assessed on the same set of words. Thus, our study was designed to examine both similarities and differences in lexical acquisition between Greek and US children assessed using the LDS.

\section{Goals of the study}

The present study used LDS data obtained for 273 Greek toddlers to address the following questions: (a) What were the effects of age group and gender on LDS vocabulary scores in this Greek sample? (b) How did lexical acquisition for this Greek sample compare with acquisition for a US sample of the same general size and age range? (c) how did percentage use scores in this Greek sample compare with percentage use scores reported for a comparable US sample? (d) How did various word classes on the LDS 'fill up' in the lexicons of Greek and US children as a function of vocabulary size? and (e) How did percentage use scores in Greek late talkers compare with those of younger Greek children with vocabularies of the same size? 
TA B LE I. Demographic information by age group for Greek sample

\begin{tabular}{|c|c|c|c|}
\hline & I ; 6-I ; I I $(N=40)$ & $2 ; 0-2 ; 5(N=78)$ & $2 ; 6-2 ;$ I I $(N=$ I 55$)$ \\
\hline \multicolumn{4}{|l|}{ Age in months } \\
\hline Mean $(S D)$ & $20 \cdot 6(\mathrm{I} \cdot 8)$ & $26 \cdot 70(1 \cdot 7)$ & $33 \cdot 0(2 \cdot 0)$ \\
\hline \multicolumn{4}{|l|}{ Gender } \\
\hline Boys :Girls & $20: 20$ & $34: 44$ & $79: 76$ \\
\hline \multicolumn{4}{|l|}{ Birth weight (gr.) } \\
\hline Mean $(S D)$ & $3172 \cdot 3(521 \cdot 8)$ & $3151 \cdot 87(632 \cdot 8)$ & $3198 \cdot 09(5 \mathrm{I} 2 \cdot \mathrm{I})$ \\
\hline \multicolumn{4}{|l|}{ Mother's age } \\
\hline Mean $(S D)$ & $30 \cdot 58(4.39)$ & $33 \cdot 00(4 \cdot 54)$ & $32 \cdot 67(4 \cdot 54)$ \\
\hline \multicolumn{4}{|l|}{ Mother's education } \\
\hline Mean $(S D)$ & $2 \cdot 86(I \cdot 05)$ & 3. I I $(0.95)$ & $2 \cdot 85(\mathrm{I} \cdot 07)$ \\
\hline \multicolumn{4}{|l|}{ Family income } \\
\hline Mean $(S D)$ & $3 \cdot I_{5}(\mathrm{I} \cdot \mathrm{OI})$ & $2.75(0.90)$ & $2.82(0.91)$ \\
\hline
\end{tabular}

\section{METHOD}

\section{Participants}

The present study involved 273 toddlers who were recruited from non-emergency pediatric appointments. All children came from middle-class monolingual Greek-speaking families, with $77 \%$ living in urban areas. Most of the children $(86 \%)$ were full-term and had no major health problems; $46 \%$ of the children had older siblings, $32 \%$ were only children, 2 I \% were first born and I \% were twins. Many of the children were attending daycare, and $45 \%$ were cared for part-time by grandparents. Participants were divided into three age groups: I;6-I III, 2;0-2; 5 and 2;6-2; I I. Table I presents demographic information by age group.

For analyses comparing Greek LDS data with US LDS data, the 274 children aged I; 6 to 2; I I who served as the LDS normative sample in the US (Achenbach \& Rescorla, 2000; Rescorla \& Achenbach, 2002) served as a comparison group. These children were recruited as part of a general population survey of households in forty states and matched the US census in terms of socioeconomic status (SES) and racial/ethnic diversity. As in the Greek sample, participants were divided into three age groups: I; 6-I ; I , $2 ; 0-2 ; 5$ and 2;6-2; I I. An adaptation of Hollingshead's (1975) occupation codes for the parent with the highest-status job was used to code SES, yielding $18 \%$ lower, $45 \%$ middle and $31 \%$ upper SES (6\% missing). Ethnicity of the sample was $57 \%$ white, $22 \%$ African-American, I $3 \%$ Latino and $9 \%$ other.

\section{Measure}

Mothers completed the Greek version of the LDS, which is an adaptation of the English version (Rescorla, I989). The English LDS contains a list 
of 3 Io words grouped into fourteen semantic categories, namely 'food' (32 words), ‘toys' ( I I words), 'outdoors' ( I I words), 'animals' (2 I words), 'body parts' ( 2 I words), 'places' (8 words), 'actions' ( 56 words), 'household' (3 I words), 'personal' ( I 4 words), 'people’ ( 5 words), 'clothes' ( I 7 words), 'vehicles' ( I o words), 'modifiers' (3 I words) and 'other' (32 words).

The adaptation of the LDS into Greek had two goals: (a) to create an inventory that would be as comparable as possible to the English inventory and (b) to develop a sensitive tool for evaluating early lexical development in Greek children. To accomplish these two goals, the structure of the Greek LDS was kept as close as possible to the original American instrument, but cultural and linguistic factors were taken into account in making the adaptation. Thus, the Greek adaptation of the LDS followed the same general strategy employed in adapting the CDI into languages other than English (Bleses et al., 2008a; Jackson-Maldonado et al., I 993; Maital et al., 2000).

The first step in the adaptation process was to translate the 3 ro words comprising the English LDS into Greek and then to back-translate the Greek into English. The translation was a collaborative effort of three Greek-English bilingual speakers, and the back-translation was carried out by two Greek-English bilingual psychology students. Based on the back-translation, 22 words in the Greek version were modified. In the second step, this Greek translation was administered to a pilot sample of twenty middle-class, Greek-speaking mothers of first-born children at the age of $\mathrm{I} ; 6$ to 2 ; 0 . Mothers were encouraged to write in any other words that their children produced that did not appear on the list, as well as to indicate words on the list that referred to objects or actions that are not common for Greek children. Word frequencies were calculated for each item on the list of the added items.

These pilot data for twenty children guided the third step in the adaptation process, in which adjustments were made in the Greek checklist to take into account cultural as well as linguistic factors. Twenty-six English words were omitted, because they did not seem relevant to Greek toddlers' experience based on data on the acquisition of Greek coming from parent reports, home observations and laboratory studies (Keller et al., 2003). These included some words referring to foods (e.g. 'cereal'), toys (e.g. 'teddy bear') and animals (e.g. 'turkey'). Additionally, some words describing body parts, personal items, places, clothes and actions were omitted because Greek has only one word for two different referents, while in English these referents have two different words (e.g. 'toe' and 'finger' in Greek are referred to by the word dhactylo, 'home' and 'house' in Greek are referred to by the word spiti, 'watch' and 'clock' in Greek are referred to by the word roloi, 'mittens' and 'gloves' in Greek are referred to by the word ghadia, 'nap' and 'sleep' in Greek are referred to by the word kimame, 
TABLE 2. Words exchanged from the US to the Greek version of the $L D S$

\begin{tabular}{ll}
\hline 26 deleted English words & 26 substituted Greek words \\
\hline cereal & tomato \\
crackers & yogurt \\
drink & carrot \\
hamburger & chips \\
hotdog & chocolate \\
soda & potato \\
teddy bear & bucket \\
bug & sea \\
turkey & butterfly \\
finish & fly \\
dinner & sheep \\
knock & lamp \\
lunch & cry \\
pattycake & leave \\
penny & mistake \\
light & fall \\
off & dress \\
out & ride \\
Sesame Street & bag \\
shut up & button \\
toe & never \\
home & don't \\
mittens & Pokemon \\
watch & godmother \\
nap & godfather \\
get & tower \\
\hline & \\
\hline &
\end{tabular}

and 'get' and 'take' in Greek are referred to by the word perno). The twenty-six omitted words were replaced by twenty-six alternate words from the list of added items that had very high frequency counts for the twenty Greek children in the pilot sample. Most of these twenty-six words replaced an English word in the same category (e.g. 'tomato' replaced 'cereal', 'butterfly' replaced 'bug'), but this was not always the case. The twenty-six exchanged words are presented in Table 2. Thus, the final Greek word checklist included 3 ro words divided into the same fourteen semantic categories as the English version, but the number of words in the various categories was not always identical to the number in the original version.

Finally, it should be noted that nouns, adjectives and pronouns were listed in the Greek LDS only in their singular masculine form (e.g. kalos 'good', krios 'cold', katharos 'clean'). Verbs were listed in the first singular (e.g. dhino 'I give', vlepo 'I see', thelo 'I want'). Mothers were instructed to mark a word as existing in the child's vocabulary if it occurred in identical or derived morphological form. 
TABLE 3. Vocabulary size by age group for Greek sample $(N=273)$

\begin{tabular}{lrrrrrr}
\hline Age range & Mean & $S D$ & Range & $25 \%$ ile & $50 \%$ ile & $75 \%$ ile \\
\hline I;6-I; I I & $56 \cdot 75$ & 5 I 04 & $\circ-244$ & 24 & 39 & 75 \\
$2 ;$ O-2; 5 & I62.10 & $86 \cdot 09$ & $0-308$ & 93 & I 75 & 235 \\
$2 ; 6-2 ;$ I I & 2 I $6 \cdot 58$ & $77 \cdot 82$ & I5-3 I0 & I 78 & 243 & 278 \\
\hline
\end{tabular}

\section{Procedure}

The researchers distributed 500 questionnaires to area pediatricians, who asked parents visiting the clinic for non-emergency appointments to complete the questionnaire while in the waiting room. The questionnaire was accompanied by a letter to the families. Approximately $55 \%$ of the families invited to participate completed the LDS. Each mother was asked to mark on the list the words her child said spontaneously, to indicate if the child used phrases, to write down five of the child's best phrases, and to fill in items of demographic information and the child's medical background. The form also provided the opportunity for mothers to write in additional words, but these words were not included in any of the analyses described below.

Data collection procedures for the US sample, as reported by Rescorla and Achenbach (2002), involved home interviews conducted by trained survey staff. Mothers of children in the I ; 6 to 2 ; I I range were interviewed using both the LDS and the Child Behavior Checklist for ages $\mathrm{I} \cdot 5$ to 5 years. Completion rate for the full $\mathrm{CBCL} / \mathrm{I} \cdot 5-5$ sample was $94 \%$.

\section{RESULTS}

\section{Vocabulary size}

When LDS Total Vocabulary scores were analyzed in a 2 (gender) $\times$ 3 (age group) ANOVA, the effect of age was highly significant, as would be expected $\left(F(2,267)=71 \cdot 34, p<0.0001, \eta^{2}=0 \cdot 35\right)$. As can be seen in Table 3 , there was substantial growth in expressive vocabulary across this age range, increasing from a mean of $56 \cdot 75$ words $(S D=5 \mathrm{I} \cdot 0)$ at $\mathrm{I} ; 6$ to I $;$ I I to I $62 \cdot \mathrm{I}$ O words $(S D=86 \cdot \mathrm{I})$ at $2 ; 0$ to $2 ; 5$, to $2 \mathrm{I} 6 \cdot 58(S D=77 \cdot 8)$ at $2 ; 6$ to $2 ; \mathrm{I}$ I. As has been found in other studies, there were large individual differences in the rate of growth of productive vocabulary, as indicated by both the $S D$ s and the ranges within each age group (o to 244 words, o to 308 words, and I 5 to 3 Io words). Girls had significantly higher vocabulary scores than boys, but the effect size was small $\left(F(\mathrm{I}, 267)=4.23, p<0.037, \eta^{2}=0.02\right)$. The age $\times$ gender interaction was not significant.

When these data for the Greek LDS are compared with those reported by Rescorla and Achenbach (2002), it appeared that vocabulary scores for Greek children were lower than those reported for US children in the 


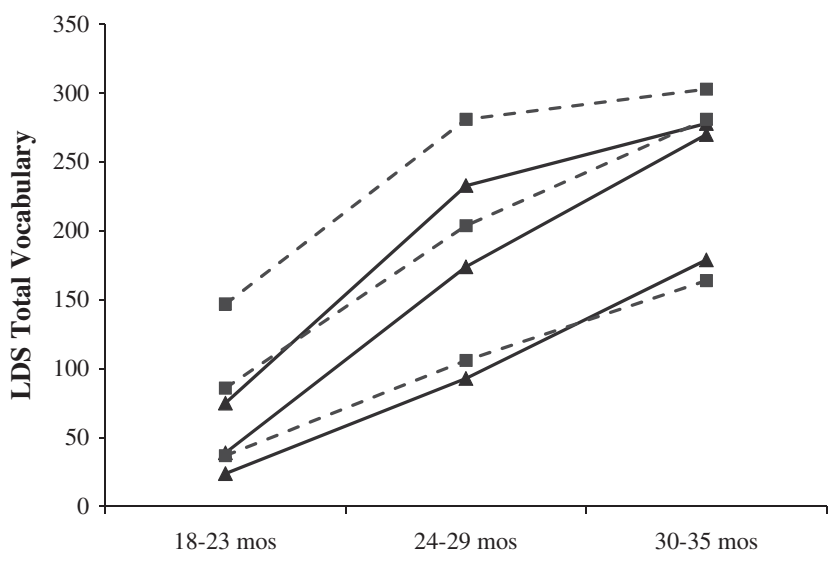

Age Group

Fig. I. LDS vocabulary scores for the Greek and US samples by age: $25^{\text {th, }} 5$ oth and $75^{\text {th }}$ percentiles.

same three age groups: $104.63(S D=83.7)$, i $84.20(S D=97.9)$ and 226.54 $(S D=9 \mathrm{I} \cdot 8)$. To test if the apparent difference in vocabulary size between Greece and the US was significant, a 2 (gender) $\times 3$ (age group) $\times 2$ (country) ANOVA was run by merging the Greek sample with the US sample. The effect of country was significant $\left(F(\mathrm{I}, 535)=\mathrm{I} \mathrm{I} \cdot 68, p<0 \cdot 00 \mathrm{I}, \eta^{2}=0 \cdot 02\right)$. Surprisingly, the country $\times$ age group interaction was not significant, although inspection of the means indicates a much larger difference for the youngest age group ( 48 words) than for the older two age groups ( 22 and Io words, respectively). Post-hoc comparisons for the three age groups using $t$-tests indicated that the country effect was only significant for the $\mathrm{I} ; 6$ to I ; I age group $(t($ I 39$)=3.37, p<0.00 \mathrm{I})$. Additionally, for the youngest age group only ( $\mathrm{r} ; 6$ to I ; I $)$ ), the $S D$ was much smaller in Greece than in the US (5I.0 vs. $83 \cdot 7$ ), whereas the $S D$ s were more similar in $2 ; 0$ to $2 ; 5$ age group ( $86 \cdot$ I vs. $97 \cdot 9)$ and the $2 ; 6$ to 2 ; I I age group $(77 \cdot 8$ vs. $9 \mathrm{I} \cdot 8)$.

To obtain a more fine-grained developmental picture of increases in vocabulary score with age for the Greek sample, the 25th, 5oth and $75^{\text {th }}$ percentile values were plotted for each 6-month age bracket. As depicted in Figure I, all three lines representing the $25^{\text {th }}$, the 5 oth and 75th percentile for Greek children showed a generally steady increase. However, children at the $75^{\text {th }}$ percentile (more rapid vocabulary learners) reached the 200-word point earlier than children at the 5oth percentile, while children at the $25^{\text {th }}$ percentile (slow vocabulary learners) did not approach the vocabulary level of 200 words until the age of 2;II. 
Inspection of the $25^{\text {th }}$, 5oth and $75^{\text {th }}$ percentile lines for the US sample (see Figure I) indicates that US children manifested a similar pattern. Additionally US children at the $75^{\text {th }}$ and 5 oth percentiles had larger vocabularies than Greek children in the I; 6 to I; I I and 2;0 to 2; 5 age brackets, whereas at the $25^{\text {th }}$ percentile they were quite comparable to the Greek children.

A commonly used benchmark for language delay at around 2;0 is fewer than 50 words of vocabulary (Rescorla, I 989, Rescorla \& Achenbach, 2002). The percentage of children with fewer than 50 words on the LDS was calculated for both the Greek and the US data by age group. For the youngest age group ( I ; 6 to I ; I I), $58 \%$ of the Greek children and $32 \%$ of the American children had reported vocabularies of fewer than 50 words, consistent with the significant difference in mean vocabulary score across the two countries at this age. In contrast, the percentages of children with fewer than 50 reported words were very similar across countries for the 2 ; 0 to $2 ; 5$ age group ( $13 \%$ in Greece vs. I $2 \%$ in the US) and identical for the $2 ; 6$ to 2 ; I I age group $(6 \%)$. This suggests that Greek toddlers may be somewhat slower than American toddlers to acquire vocabulary in the $1 ; 6$ to I; I I age bracket, but comparable in the other two age brackets.

\section{Vocabulary composition}

The percentage of the 273 Greek children and the 274 US children reported to use each of the 284 words that were on both language versions of the LDS was calculated (e.g. $95 \%$ of Greek and $97 \%$ of US children were reported to use the word 'daddy'; $82 \%$ of Greek children and $92 \%$ of US children were reported to use the word 'eye'). When a Pearson correlation is calculated between 'cases' across 'items' the resulting statistic is conventionally referred to as a $q$ correlation, to differentiate it from the typical Pearson $r$, which is calculated between 'items' across 'cases'. In this study, the 'items' were the 284 words in common between the original LDS and the Greek adaptation, and the 'cases' were the US (i.e. percentage use scores for each word for the 274 children in the US sample) and Greece (i.e. the percentage use scores for the 284 words for the 273 children in the Greek sample). The resulting $q$ correlation has all the statistical properties of the more familiar $r$, that is, it can range from $-0 \cdot \mathrm{I}$ to $\mathrm{O}^{\mathrm{I}} \mathrm{I}$, and a correlation of $\geqslant 0.50$ is considered 'large' according to Cohen ( 1988 ).

The $q$ correlation between LDS percentage use scores for the US and Greek samples was $0.5 \mathrm{I}(p<0.00 \mathrm{I})$. When correlations were calculated between Greek and US word frequencies for children in the same vocabulary size bracket (e.g. <50 words, 50-99 words, Ioo-I49 words, etc.), the correlations were in the same general range (from 0.42 for $>250$ words to 0.63 for 50-99 words). We also calculated Greek-US $q$ correlations for 
percentage use scores in the three age groups separately. The resulting $q$ correlations were 0.58 for the $\mathrm{I} ; 6$ to $\mathrm{I} ; \mathrm{I}$ I age group, 0.50 for the 2 ; 0 to $2 ; 5$ age group, and 0.47 for the $2 ; 6$ to 2 ; I I age group, which are in the same range as the results by vocabulary size bracket. Although these correlations were all significant, they are much lower than correlations of percentage use scores obtained among US samples. For example, Rescorla et al. (200 I) reported a $q$ correlation of 0.86 between a Pennsylvania sample of 422 children and the children of comparable age from the Fenson et al. (I 994) norming sample for the CDI for the 280 words in common between the two checklists. When $q$ correlations were calculated between the US national survey sample used in the present study and the Pennsylvania sample and CDI samples used by Rescorla et al. (200I), the resulting $q$ correlations were, respectively, 0.85 (for 3 Io words) and 0.80 (for 280 words). Thus, the $q$ correlation obtained in the present study suggests that there are some substantial differences in word frequencies in this Greek sample when compared to scores for US toddlers, despite a considerable overlap in the words most commonly reported.

To further compare percentage use scores reported for Greek toddlers with those reported for American toddlers, we tabulated the 50 LDS words with the highest percentage use scores for the Greek and the US samples. This yielded a total of 75 words, 25 of which were among the 50 words with the highest percentage use scores in both samples. These 25 words included 4 people words ('mommy', 'daddy', 'grandma' and 'baby'), I 5 common nouns ('ball', 'banana', 'milk', 'water', 'car', 'cat', 'dog', 'bird', 'ear', 'eye', 'hair', 'nose', 'mouth', 'shoes' and 'bath'), I verb ('love'), 2 pronouns ('mine', 'me') and 3 miscellaneous words ('hi/hello', 'no', and 'yes').

We did a similar 'top 50' word analysis separately by age group in the two samples. As would be expected, there was a stronger association between the 50 words with the highest percentage use scores across adjacent age groups in the same sample (e.g. $q$ correlations of 0.80 and 0.9 I for the Greek sample and 0.92 and 0.92 for the US sample) than across the same age groups in different samples $(0.47$ to 0.58$)$. There were 16 words present in the 'top 50' list for all three age groups in both samples ('mommy', 'daddy', 'baby', 'dog', ‘cat', ‘eye', 'ear', 'nose', ‘no', 'hi/hello', 'milk', ‘water', 'shoes', 'bath' and 'mine'), and another four words present in five of the six subsamples ('hair', 'car', 'grandma' and 'ball'). In contrast, some words were present in the 'top 50' words for all three US lists but for none of the Greek lists (e.g. 'juice', 'book', 'byebye', 'cookie', 'eat', 'cup', 'go', 'please', 'thank you'), whereas other words were present in all three 'top Iо' Greek lists but for none of the US lists (e.g. 'potato', 'bread', 'chicken', 'this', 'good', 'bad' and 'doodoo'). These words with high percentage use scores in one country only probably reflect different cultural 
practices in the two countries, such as the foods that children typically eat and the social routines emphasized.

In both sets of the 50 highest percentage use words, common nouns constituted the largest group of words, namely $50 \%$ in Greece (25 words) and $56 \%$ in the US ( 28 words). The number of adjectives ( 3 in Greek, 2 in English) and verbs (5 in Greek, 6 in English) were comparable in the two languages. On the other hand, the Greek 'top 50' lexicons had more people words ( 7 vs. 4 ), and more pronouns/prepositions/adverbs) (6 vs. 3), while the US 'top 50' lexicons had more routine words (7 vs. 3 ). Common nouns with high percentage use scores for both samples included words for foods, body parts, animals, household/personal items, clothes, toys, outdoor objects and places, and vehicles. Thus, children in both Greece and the US were highly likely to acquire words that referred to important and ubiquitous objects in their everyday lives and that represent a diverse set of semantic categories.

In the next analysis, a difference score was calculated for each of the 284 words on both the US and Greek versions of the LDS. When the Greek percentage use score was subtracted from the US percentage use score, difference scores ranged from -0.52 to 0.52 , with a mean difference score of -0.04 and a $S D$ of 0.16 . When \pm I $S D$ was used as a cut-point for these difference scores, there were 38 words more commonly reported for US toddlers and 47 words more commonly reported for Greek toddlers. The distributions of these words were similar in most respects. Slightly more than half the words in both sets were common nouns $(58 \%$ of the US > Greek words and $55 \%$ of the Greek > US words). Percentages of adjectives/modifiers ( $13 \%$ US vs. I $7 \%$ Greek), action words/verbs ( г $6 \%$ US vs. $9 \%$ Greek) and 'other' words ( I I US vs. I $3 \%$ Greek) were roughly comparable in the two countries, but words denoting people were more commonly found in the Greek > US set ( $3 \%$ in US vs. $6 \%$ in Greece), with 'uncle', 'grandma' and 'aunt' having much higher frequencies in Greece than the US and 'pet name' having higher frequency in the US than in Greece.

For the final percentage use analysis, we compared the Greek and US samples in terms of OPPORTUNITY sCOREs for five basic word classes as a function of the vocabulary size of the children. By opportunity score, we mean the percentage of words in a given LDS category that a child has acquired. The first step in this analysis was to divide the children in each sample into six vocabulary size classes (<50 words, 50-99 words, I words, I 50-I 99 words, 200-249 words and 250 words or more). Next, the words on the LDS were regrouped into five basic word class categories (common nouns, people words, verbs, adjectives and closed-class words), drawing on definitions suggested by Bates et al. (1 994). For this regrouping, animal sounds (e.g. 'woofwoof', 'meow'), baby-talk words ('booboo', 'yumyum') and routine words ('hi, hello', 'yes', 'no', 'byebye', 'welcome', 
'please', 'thank you') were not entered in the statistical analysis, because they occupy a very small proportion of the total checklist (less than $4 \%$ ). As described below, this regrouping was done separately for the Greek and US versions of the checklist, as 26 words were different across the two language versions.

For the category of common nouns, all LDS words in the categories 'foods', 'toys', 'outdoors', 'animals', 'body parts', 'vehicles', 'household', 'personal', 'places' and 'clothes' were used, plus the words 'bath', 'breakfast', 'dinner', 'any number' and 'any letter'. The word 'lunch' was also in the US category of common nouns, which contained I 83 words $(59 \%$ of the entire checklist). The Greek category contained many of these same words, plus i 5 of the 26 additional Greek words, for a total of i 8 I words ( $58 \%$ of the entire checklist).

For the US sample, people words included all i 5 words in the English category of 'people words' ( $5 \%$ of the total checklist), whereas the Greek category had an additional 3 words ( 8 words, $6 \%$ ).

The US category of verbs included all words from the LDS category of 'actions' that are typically used as main verbs ('have' was omitted), for a total of 44 verbs ( $14 \%$ of the checklist). The Greek category of verbs included most of these same words plus 7 more verbs from the 26 additional Greek words, for a total of 47 verbs ( $5 \%$ ).

Both the US and the Greek category of adjectives contained 26 words ( $8 \%$ of the checklist). These words consisted of all the adjectives in the LDS 'modifiers' category.

Finally, the category 'closed-class words' included prepositions, adverbs, pronouns, possessives and question words (e.g. 'up', 'down', 'in', 'outside', 'off', 'out', ‘on', 'under', 'away', 'more', 'never', 'here', 'there', 'me', 'mine', 'my', 'you', 'myself', 'this', 'that', 'where', 'why' and 'what'). The US version had 22 items $(7 \%)$ and the Greek version had 2 I items ( $7 \%)$. It should be noted that auxiliaries are not among the words on the LDS in either Greek or English, and therefore the closed-class items analyzed were solely what might be termed 'relational' words rather than 'functional' words.

For this analysis, word opportunity scores for each child were obtained by dividing the number of words reported for a given category by the number of possible words in that category on the checklist. These word opportunity scores describe the development of each word class separately, hence the rate in which each word class 'fills up'. The percentages were converted to arcsines for the opportunity score analysis, but the results are reported and displayed in terms of regular percentages. Opportunity scores were submitted to a $2 \times 5$ multivariate analysis of variance (MANOVA), with country and vocabulary size as the independent variables and the five word classes as the dependent measures. Because five word classes were 
tested, $p<0.0 \mathrm{I}$ was used as the alpha level for this analysis. Opportunity scores by word class at each vocabulary size level are displayed in Figures $2 \mathrm{a}$ (Greek) and 2b (US).

As would be expected, vocabulary size yielded a very large and highly significant effect in both countries, which can be seen in Figures $2 \mathrm{a}$ and $2 \mathrm{~b}$. That is, children who had larger LDS Total Vocabulary scores had progressively larger percentages of words in each category. Every pair-wise contrast across adjacent vocabulary sizes was significant using StudentNeuman-Keuls' post-hoc tests. That is, in every word class, children had a significantly higher opportunity score as vocabulary size increased one bracket (e.g. from $<50$ words to 50-99 words). The category of people words (which contained I 5 English words and i 8 Greek words) tended to fill up earliest in both countries. In both countries, with increasing vocabulary size the five word classes became increasingly similar in opportunity score percentages.

The country $\times$ vocabulary size MANOVA yielded only one significant effect of country, namely that for closed-class words $(65 \%$ vs. $55 \%$, $\left.F(\mathrm{I}, 527)=\mathrm{I} 3.92, p<0.00 \mathrm{I}, \eta^{2}=0.03\right)$. In addition the country $\times$ vocabulary size interaction was significant and large for closed-class words $\left(F(\mathrm{I}, 527)=\mathrm{I} 9.10, p<0.00 \mathrm{I}, \eta^{2}=0 . \mathrm{I}_{5}\right)$. As can be seen in Figure 3 , Greek children had higher percentages of closed-class words at all vocabulary sizes until the 200 -word level. It should be noted that the country $\times$ vocabulary size interaction was also significant for the other four word classes, but the effect sizes were generally smaller (nouns $=0.04$, people $=0.04$, verbs $=0.06$ and adjectives $=0 \cdot 12)$.

\section{Late talkers}

Late talkers were identified in both the Greek and US samples. Because previous LDS studies have identified late talkers at 2 ; 0 or older, these analyses were restricted to children in the 2 ; 0 to 2 ; I I age range. Late talkers were identified by the criterion of an LDS vocabulary of fewer than 50 words at 2 ; 0 or older (Rescorla, I 989). In this study, I 9 of 233 children in the Greek sample ( $8 \%$ ) and 16 out of I 73 children in the US sample (9\%) met this criterion. In the Greek sample, late talkers had a mean vocabulary of 28 words $(S D=\mathrm{I} 3 \cdot 26)$, compared to a mean vocabulary of $2 \mathrm{I}_{5}(S D=$ $70 \cdot \mathrm{I})$ in their age-mates. Similarly, in the US, late talkers had a mean vocabulary of $2 \mathrm{I}$ words $(S D=\mathrm{I} 2 \cdot 86)$, compared to a mean vocabulary of $223 \cdot 18$ words $(S D=8 \mathrm{I} \cdot \mathrm{I} 8)$ in their age-mates. As would be expected, both differences were highly significant $(t(\mathrm{I} 43.48)=33.00, p<0.00 \mathrm{I}$; $t(\mathrm{I} 49 \cdot 05)=27 \cdot 92, p<0 \cdot 00 \mathrm{I}$, respectively).

In both samples, percentage use scores in the late talkers were compared with these scores in children aged I;6-I; I I with lexicons of the same 

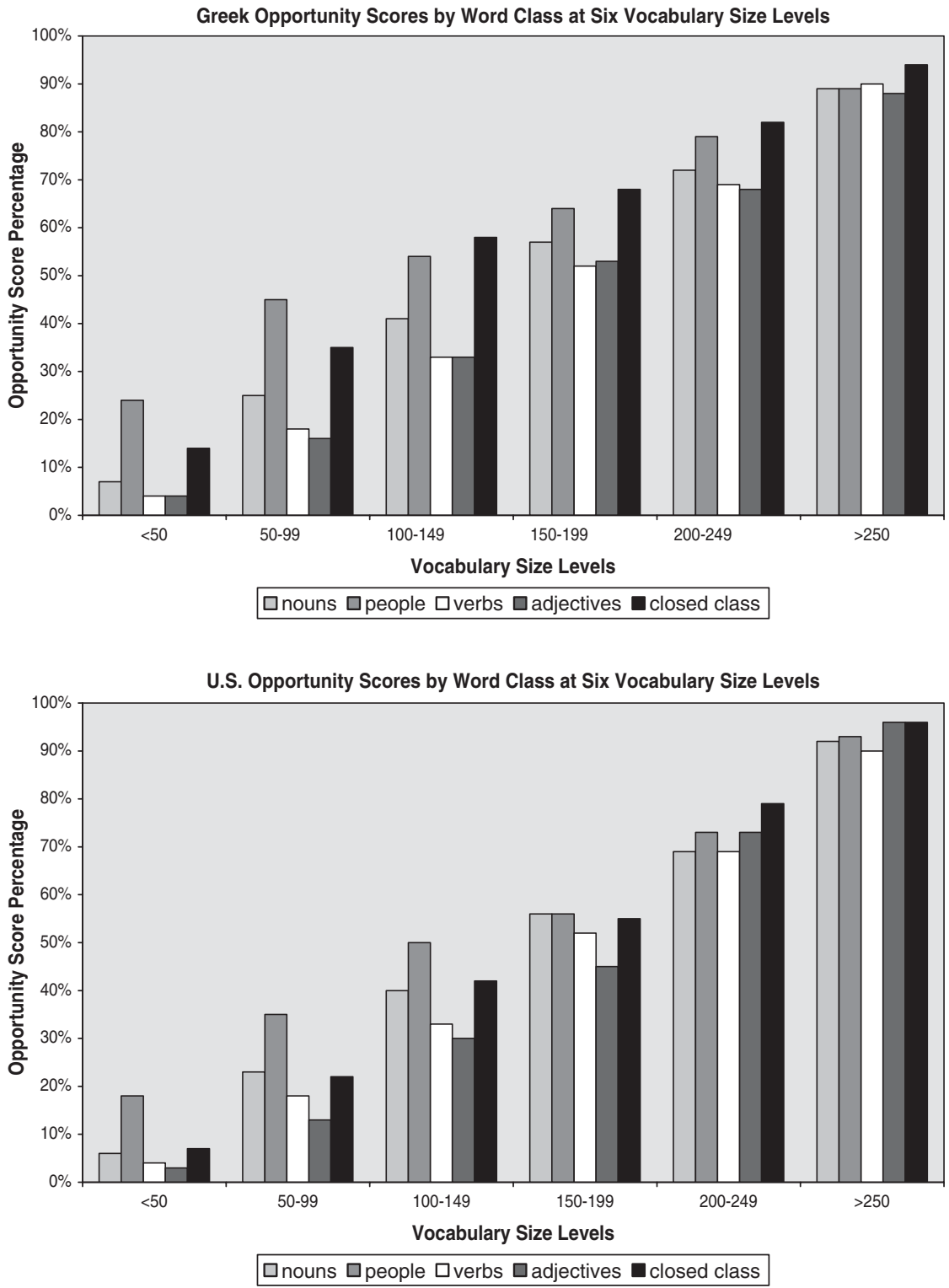

Fig. 2. Opportunity scores for different word classes by vocabulary size level in Greek and US samples. 


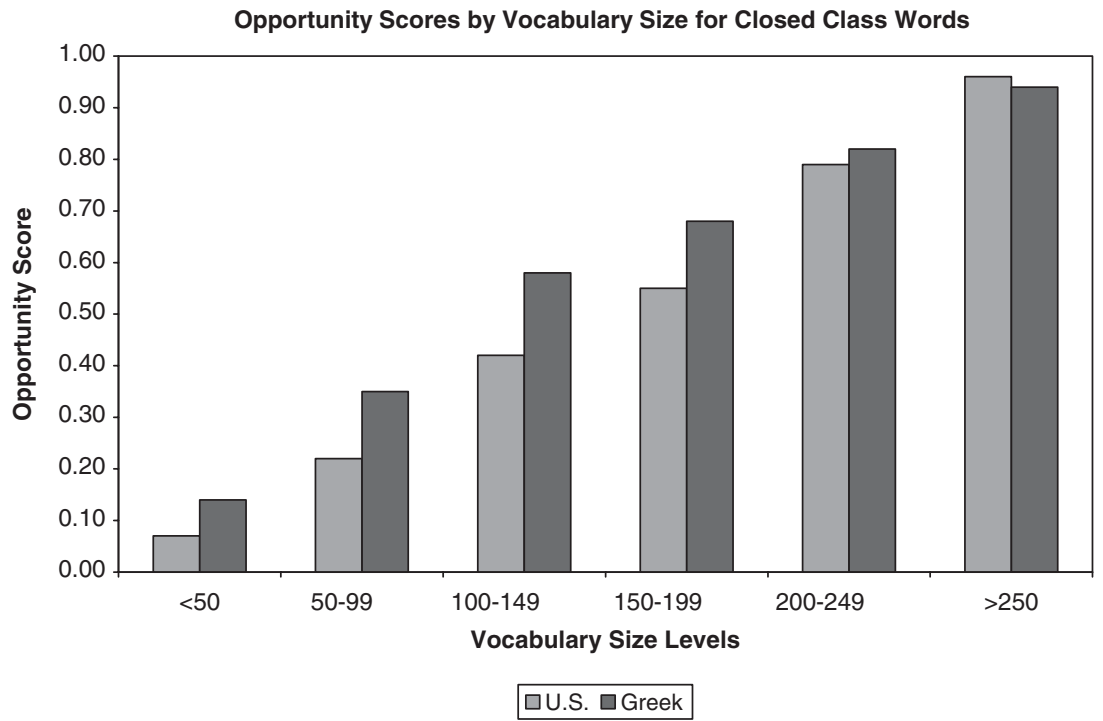

Fig. 3. Opportunity scores for closed-class words by vocabulary size level for Greek and US children.

size $(<50$ words). For the Greek sample, when word frequencies for the I9 late talkers and the 23 children age I;6-I; I I with $<50$ words were correlated, the resulting $q$ correlation was 0.85 ( $p<0.00 \mathrm{I})$, indicating a high degree of similarity in percentage use scores. Similarly, in the US sample, the parallel $q$ correlation was 0.83 ( $p<0.00 \mathrm{I})$, indicating that percentage use scores were very similar for late talkers aged 2 ; 0 to 2 ; I I with $<50$ words and for children aged I; 6 to 2 ; I I with $<50$ words. On the other hand, the $q$ correlation between Greek and US late talkers was only $0.46(p<0.00 \mathrm{I})$, or the same order of magnitude as the Greek-US $q$ correlation for the full sample.

Finally, the 50 words in the lexicons of the Greek and US late talkers with the highest percentage use scores were identified. There were I 7 words present in both lexicons ('mommy', 'daddy', 'grandma', 'milk', 'water', 'juice', 'hi/hello', ‘no', ‘ball', 'dog', ‘bath', 'meow', 'banana', 'down', 'cake', 'egg' and 'chicken'). When the 50 words were classified by word class, some notable differences emerged. For example, common nouns comprised 32 of the 50 words for the US late talkers but only 20 of the 50 words for the Greek late talkers. In contrast, closed-class words were much less common in the US lexicons than the Greek lexicons (2 vs. Io words). People words were somewhat less common in the US than the Greek lexicons (5 vs. 8 ), but verbs were slightly more common (4 vs. 2). Adjectives were 
rare in both lexicons ( $\mathrm{I}$ vs. 2, in the US and Greek, respectively), whereas greetings and miscellaneous other words were rather common (6 in the US and 8 in the Greek lexicons). Thus, the late talker findings mirrored the findings for the full sample in that closed-class words were more frequently reported for Greek children, whereas common nouns were more predominant in the US lexicons, although they comprised the largest class of words in both languages.

\section{DISCUSSION}

The present study is the first research to examine vocabulary size and composition in a large sample of Greek children aged I; 6 to 2; I I and to compare these findings with findings for US children using a variety of statistical procedures. The few previous studies of lexical development in Greek children have used very small samples, rather than the large sample, cross-linguistic vocabulary checklist paradigm employed in this research. For both vocabulary size and vocabulary composition, cross-linguistic findings indicated both important similarities and some interesting differences.

\section{Vocabulary size findings}

Consistent with much previous literature, girls had slightly larger reported vocabularies than boys, but the effect size was small. Additionally, LDS scores increased markedly with age in both countries, as would be expected. However, in the youngest age group ( I; 6 to I ; I I), Greek toddlers had a significantly smaller mean and $S D$ for LDS vocabulary score than US toddlers. Similarly, $58 \%$ of Greek children in the youngest age group had LDS scores of fewer than 50 words, whereas only $32 \%$ of US children had scores this low. In contrast, in the subsequent two age groups $(2 ; 0$ to $2 ; 5$ and $2 ; 6$ to $2 ;$ I I), mean LDS scores, $S D$ s and percentage of children with fewer than 50 words were very similar across the two samples.

The fact that Greek children had smaller LDS vocabularies than US children in the youngest age group ( $1 ; 6$ to I ; I I) but not at later ages is consistent with CDI studies comparing children from the UK, Australia and New Zealand with those from the US (Bavin et al., 2008; Hamilton, Plunkett \& Schafer, 2000; Reese \& Read, 2000). This suggests that US parents have a tendency to report larger vocabularies early in the acquisition period than parents from other societies, including other English-speaking societies. What is not clear from these findings is whether this reflects an actual difference in lexicon size (i.e. US parents concentrate more on fostering early word learning, so US children acquire words earlier than children in other countries) or a reporting difference (i.e. US parents are more liberal in crediting children with words as acquired than parents in other societies, 
who set a stricter criterion for acquisition). Of course, both actual differences in lexicon size and reporting factors could be contributing to this difference between US children and children from other countries.

Another possible reason that Greek lexicons were smaller than US lexicons in the youngest age group is that Greek parents completing the LDS alone in a pediatrician's waiting room might have been less willing to credit words as acquired when they were somewhat unsure about their status than US parents completing the LDS during home interviews conducted by trained survey staff. However, this explanation would not apply to the findings from the UK, Australian and New Zealand studies.

Finally, one might hypothesize that vocabulary acquisition may accelerate more slowly in Greek than in English because Greek is a more morphologically complex language. By this argument, because Greek children are exposed to more morphological variants of the same word than US children, they may be slower to form phonological representations of words. However, a contrasting view is that a regular and transparent morphology may assist in assigning word categories and thus foster earlier lexical acquisition (Leonard, 2000). Additionally, this explanation would not apply to children learning English in different countries. In sum, cultural differences appear to be the best explanation for these lexicon size findings, but further research is needed to determine if they are based on actual or reported lexicon size differences at younger ages.

\section{Vocabulary composition findings}

Cross-linguistic word frequency findings also showed a mixture of similarities and differences. For example, the $q$ correlation for word frequency was significant $(r=0.5 \mathrm{I})$, but smaller than those reported by Rescorla and Alley (200I) for US samples. Half of the 50 most commonly reported words for Greek and US children were identical, including words such as 'daddy', 'mommy', 'cat', 'dog', 'ball', 'eye', 'nose', 'shoes', 'bath', 'yes', 'no' and 'hello/hi'.

In the set of 50 words with the highest percentage use scores in both samples, common nouns constituted the largest group of words $(50 \%$ in Greek and $56 \%$ in the US), with percentages that were quite similar. The number of adjectives and verbs in the 'top 50' set were also rather comparable in the two languages, but the Greek set had more people words and more closed-class words, while the US set had more routine words. Common nouns with high percentage use scores for both samples included words for foods, body parts, animals, household/personal items, clothes, toys, outdoor objects and places, and vehicles. Thus, children in both Greece and the US acquired words from a multiplicity of semantic categories. 
When we examined words that were much more commonly reported in one language than another, we found that $58 \%$ of the US $>$ Greek words and $55 \%$ of the Greek $>$ US words were common nouns. However, words referring to people tended to comprise a higher percentage of the Greek $>$ US set than the US > Greek set (6\% vs. $3 \%)$. This may be because Greek children have more frequent contacts with extended family members than US children, but no data relevant to this speculation were collected in this study.

Our opportunity score analysis compared the percentages of items in five word classes acquired by Greek and US children at different vocabulary size levels. The denominators for these opportunity scores comprised the number of words in the respective word classes on the checklist, and do not in any way represent possible words in these classes in Greek or English in general. One notable cross-linguistic difference was found in the opportunity score analysis. For closed-class words, there was a significant effect of country and a large country $\times$ vocabulary size interaction. This finding reflects the fact that Greek children had higher percentages of closed-class words such as prepositions/adverbs (e.g. 'up', 'never', 'here'), pronouns/possessives ('me', 'this', 'that') and question words ('where', 'why', 'what') than US children up until the 200-word level. It should be reiterated that the LDS does not include function words such as auxiliary verbs (with the exception of 'have', which can also be a main verb). Therefore, our findings about closed-class words only apply to the words we used, which are 'relational' rather than 'functional' in nature. Relational words express relations between different objects or between actions and objects (e.g. 'down', 'mine', 'outside'). That is, such words refer to temporal or spatial aspects of actions or events rather than being labels for objects or events, they can stand alone in single-word utterances and they refer to experiences the child has with a variety of referents.

Despite the early predominance of object names in early vocabularies, studies in many languages including English, German, Hebrew and Korean demonstrate that relational words are very common among the earliest words (Dromi, I 987 ; Choi \& Gopnik, I 995 ; Kauschke \& Hofmeister, 2002; Nelson, r973). However, Tomasello and Merriman (r995) note that although relational words may appear relatively early, they may not be used in the same way by children as by adults. Whereas adults use them to specify a relation between objects or a location and an object, children may use them to refer to events.

According to Gentner and Boroditsky (200I), the meaning of relational words is formed by a particular linguistic system to a greater degree than is the case for concrete nouns. Thus, the differences observed between Greek and American toddlers in the acquisition of relational words may be due to differences in the linguistic input. Anecdotal observations 
of three Greek mother-child dyads reveal that on average $85 \%$ of the mothers' utterances addressed to their children aged I; I0, 2;0 and 2;3 contained a relational word, while the corresponding mean percentage in children's speech was $75 \%$. However, so far there are no systematic studies comparing the amount of relational words contained in childdirected speech in Greek and English. Another characteristic of the input that may affect the acquisition of relational words is the correspondence between the information encoded in relational words in different languages and the child's developmental level. In particular, Choi and Gopnik (I995) suggest that young children are interested in object names and relational words that reflect their non-linguistic cognitive development. In other words, children acquire words in the adult language that are relevant to their particular interests. These authors also propose that English relational words may not encode the kinds of relations that match to early cognitive representations. Thus, one could speculate that Greek relational words show more functional variability and encode more diverse relations between objects and actions than English words and therefore provide a better match to early cognitive representations. However, the current study did not obtain data that are relevant for examining this speculation.

It will be important in future research to see if this relatively greater predominance of pronouns, prepositions, adverbs and question words in Greek compared to US lexicons is replicated in other samples. It should be noted that the present study could not examine possible discourse or linguistic factors that might account for the apparent Greek-US difference in the acquisition of these classes of words, but this question might be fruitfully examined in future research.

\section{Greek late talkers}

The criterion of $<50$ words between 2 ; 0 and 2 ; I I to identify late talkers yielded very similar percentages in the two samples $(8 \%$ in Greece and $9 \%$ in the US). Thus, the present study indicated that Greek late talkers can be effectively identified using the LDS. Percentage use scores for Greek late talkers were very similar to those found for younger typically developing Greek children, but rather different from those of US late talkers, as indicated by the $q$ correlation findings. Common nouns comprised a larger portion of the 50 highest-frequency words for the US late talkers than for the Greek late talkers ( 32 vs. 20 words, out of 50 ), whereas closed-class words comprised a much smaller portion ( 2 vs. Io words, out of 50 ). Thus, the late talkers' findings mirrored the findings for the full sample in that closed-class words were more frequently reported for Greek children, whereas common nouns were more predominant in the US lexicons, although nouns constituted the largest class of words in both languages. 
There were 17 words present in the lexicons of both groups of late talkers ('mommy', 'daddy', 'grandma', 'milk', 'water', ‘juice', 'hi/hello', 'no', 'ball', 'dog', 'bath', 'meow', 'banana', 'down', 'cake', 'egg' and 'chicken').

Strengths of this lexical development study include that it utilized a much larger sample of Greek children than has been previously examined and that the Greek sample was directly compared with a US sample of the same size and age range. This research design allowed systematic statistical comparison of Greek and US lexical acquisition data using a variety of different analytic approaches. Thus, the present study used the LDS adapted into Greek to extend the paradigm developed in CDI cross-linguistic studies, whereby vocabulary development in different cultures is compared by using an adaptation of the English checklist.

Despite the strengths of the present study, certain limitations should also be noted. Although the Greek sample used in this study was quite large, it was somewhat homogeneous in terms of SES and geographic region. Additionally, because LDS data were collected cross-sectionally, it was not possible to track vocabulary acquisition over time in the same children. Furthermore, no direct measures of vocabulary acquisition were obtained, so generalization of the findings is limited to parent-reported vocabulary. In addition, LDS words were assigned to word classes without access to information about the way children actually used the words. Thus, assignment to word classes was by necessity somewhat arbitrary for some LDS words (e.g. words that can be either nouns or verbs, such as 'kiss' or 'hug').

This study yielded valuable findings about vocabulary acquisition in Greek, a language for which, to our knowledge, no previous studies on lexical development have been conducted with large samples. Results suggested that Greek toddlers have smaller vocabularies than US toddlers in the age range of $\mathbf{I} ; 6$ to $\mathbf{I} ; \mathbf{I}$, but that this difference disappears after about age 2 ; 0 . Additionally, the study indicated that Greek toddlers appear to focus more than US toddlers on people words and closed-class words in their early vocabularies. However, for both groups, nouns tend to predominate in early vocabularies.

\section{REFERENCES}

Achenbach, T. M. \& Rescorla, L. A. (2000). Manual for ASEBA preschool forms \& profiles. Burlington, VT: University of Vermont, Research Center for Children, Youth, \& Families.

Au, T. K., Dapretto, M. \& Song, Y. K. (1994). Input versus constraints: Early word acquisition in Korean and English. Fournal of Memory and Language 33, 567-82.

Bassano, D. (2000). Early development of nouns and verbs in French: Exploring the interface between lexicon and grammar. Fournal of Child Language 27(3), 52 I-59. 
Bates, E., Marchman, V., Thal, D., Fenson, L., Dale, P., Reznick, J. S., Reilly, J. \& Hartung, J. (1994). Development and stylistic variation in the composition of early vocabulary. Fournal of Child Language 21, 85-123.

Bavin, E. L., Prior, M., Reilly, S., Bretherton, L., Williams, J., Eadie, P., Barrett, Y. \& Ukoumunne, O. C. (2008). The Early Language in Victoria study: Predicting vocabulary at age one and two years from gesture and object use. Fournal of Child Language 35(3), $687-70 \mathrm{I}$.

Benedict, H. E. (1979). Early lexical development: Comprehension and production. Fournal of Child Language 6, I 83-200.

Bleses, D., Vach, W., Slott, M., Wehberg, S., Thomsen, P., Madsen, T. O. \& Basboll, H. (2008a). Early vocabulary development in Danish and other languages: A CDI-based comparison. Fournal of Child Language 35(3), 6r9-50.

Bleses, D., Vach, W., Slott, M., Wehberg, S., Thomsen, P., Madsen, T. O. \& Basboll, H. (2008b). The Danish Communicative Developmental Inventories: Validity and main developmental trends. Fournal of Child Language 35(3), 65 I-69.

Bornstein, M. H., Cote, L. R., Maital, S., Painter, K., Park, S.-Y. \& Pascual, L. (2004). Cross-linguistic analysis of vocabulary in young children: Spanish, Dutch, French, Hebrew, Italian, Korean, and American English. Child Development 75(4), I I I 5-39.

Camaioni, L. \& Longobardi, E. (I 995). Nature and stability of individual differences in early lexical development of Italian-speaking children. First Language I5, 203-2 I 8.

Caselli, C. M., Bates, E., Casadio, P., Fenson, J., Fenson, L., Sanderl, L. \& Weir, J. (1995). A cross-linguistic study of early lexical development. Cognitive Development Io, 159-99.

Choi, S. \& Gopnik, A. (I 995). Early acquisition of verbs in Korean: A cross-linguistic study. Fournal of Child Language 22(3), 497-529.

Christofidou, A. \& Stephany, U. (2003). The emergence of nominal inflection in Greek. In U. Sthephany \& M. D. Voeikova (eds), Development of nominal inflection in first language acquisition: A cross-linguistic perspective, 217-64. New York: Mouton de Gruyter.

Cohen, J. (1988). Statistical power analysis for the behavioral sciences, 2nd edn. New York: Academic Press.

D’Odorico, L., Carubbi, S., Salerni, N. \& Calvo, V. (200I). Vocabulary development in Italian children: A longitudinal evaluation of quantitative and qualitative aspects. Fournal of Child Language 28, $35 \mathrm{I}-72$.

Dale, P. \& Goodman, J. (2005). Commonality and individual differences in vocabulary growth. In M. Tomasello \& D. I. Slobin (eds), Beyond nature-nurture: Essays in honor of Elizabeth Bates, pp. 4I-78. London: Lawrence Erlbaum.

Dromi, E. (1987). Early lexical development. Cambridge: Cambridge University Press.

Fenson, L., Dale, P. S., Reznick, J. S., Bates, E., Thal, E. \& Phethick, J. P. (1994). Variability in early communicative development. Monographs of the Society for Research in Child Development (Serial no. 242), 59(5).

Fenson, L., Dale, P. S., Reznick, J. S., Thal, D. J., Bates, E., Hartung, J. P., Pethick, S. \& Reilly, J. S. (I 993). MacArthur Communicative Development Inventories: User's guide and technical manual. San Diego, CA: Singular.

Fenson, L., Pethick, S., Renda, C., Cox, J. L., Dale, P. \& Reznick, J. S. (2000). Short-form versions of the MacArthur Communicative Development Inventories. Applied Psycholinguistics 2I(I), 95-II 5 .

Gentner, D. \& Boroditsky, L. (200I). Individuation, relational relativity and early word learning. In M. Bowerman \& S. Levinson (eds), Language acquisition and conceptual development, pp. 215-56. Cambridge: Cambridge University Press.

Goldfield, B. A. \& Reznick, J. S. (I990). Early lexical acquisition: Rate, content, and the vocabulary spurt. Fournal of Child Language 17, I 7 I-83.

Hamilton, A., Plunkett, K. \& Schafer G. (2000). Infant vocabulary development assessed with a British communicative development inventory. Fournal of Child Language 27, $689-705$. 
Jackson-Maldonado, D., Thal, D., Marchman, V., Bates, E. \& Gutierrez-Clellen, V. (I 993). Early lexical development in Spanish-speaking infants and toddlers. Fournal of Child Language 20, 523-49.

Junker, D. A. \& Stockman, I. J. (2002). Expressive vocabulary of German-English bilingual toddlers. American Fournal of Speech-Language Pathology II, $38 \mathrm{I}-94$.

Karousou, A., Katis, D. \& Stambouliadou, C. (2008). The emergence of protowords: Empirical evidence on the gradual convergence of parameters of wordiness. Psychology: The Fournal of the Hellenic Psychological Society 15(2), i I9-38.

Kauschke, C. \& Hofmeister, C. (2002). Early lexical development in German: A study on vocabulary growth and vocabulary composition during the second and third year of life. Fournal of Child Language 29(4), 735-57.

Keller, H. (2002). Development as the interface between biology and culture: A conceptualization of early ontogenetic experiences. In H. Keller, Y. H. Poortings \& A. Schoelmerich (eds), Between culture and development. Cambridge, MA: Cambridge University Press.

Keller, H., Papaligoura, Z., Kuensemueller, P., Voleker, S. et al., (2003). Concepts of mother-infant interaction in Greece and Germany. Fournal of Cross-Cultural Psychology 34, 677-89.

Kotsakidis, H. (2003). Vocabulary acquisition and input influence in early child Greek - A study of the vocabulary spurt and function words. $\mathrm{PhD}$ dissertation, University of Göteborg.

Leonard, L. B. (2000). Specific language impairment across languages. In D. V. M Bishop \& L. B. Leonard (eds), Speech and language impairments in children: Causes, characteristics, intervention and outcome, pp. I I-30. Hove: Psychology Press.

Leopold, W. (1939). Speech development of a bilingual child. A linguist's record: Vol. I. Vocabulary growth in the first two years. Evanston, IL: Northwestern University Press.

Mackridge, P. (1985). The modern Greek grammar. Oxford: Clarendon.

Maital, S. L., Dromi, E., Sagi, A. \& Bornstein, M. H (2000). The Hebrew Communicative Development Inventory: Language specific properties and cross-linguistic generalizations. Fournal of Child Language 27, 43-67.

Natsopoulos, D. \& Xeromeritou, A. (I989). Children's and adults' perception of missing subjects in complement clauses: Evidence from another language. Fournal of Psycholinguistic Research 18(3), 3 13-40.

Nelson, K. (1973). Structure and strategy in learning to talk. Monographs of the Society for Research in Child Development $\mathbf{3 8}$ (serial no. I49).

Ogura, T., Dale, P. S., Yamashita, Y., Murase, T. \& Mahieu, A. (2006). The use of nouns and verbs by Japanese children and their caregivers in book-reading and toy playing contexts. Fournal of Child Language 33, I-29.

Patterson, J. L. (I998). Expressive vocabulary development and word combinations of Spanish-English bilinguals. Fournal of Speech and Language Pathology 7, 46-56.

Petinou, K. \& Okalidou, A. (2006). Speech pattern in Cypriot-Greek late talkers. Applied Psycholinguistics 27(3), 335-53.

Philippaki-Warburton, I. \& Spyropoulos, V. (2004). A change of mood: The development of the Greek mood system. Linguistics 42(4), 79I-8I 7 .

Reese, E. \& Read, S. (2000). Predictive validity of the New Zealand MacArthur Communicative Development Inventory: Words and sentences. Fournal of Child Language $27(2), 255^{-66 .}$

Rescorla, L. (1989). The Language Development Survey: A screening tool for delayed language in toddlers. Fournal of Speech and Hearing Disorders 54, 587-99.

Rescorla, L. \& Achenbach, T. M. (2002). Use of the Language Development Survey (LDS) in a national probability sample of children 18 to 35 months old. Fournal of Speech, Language, and Hearing Research 45, 733-43.

Rescorla, L. \& Alley, A. (200I). Validation of the Language Development Survey (LDS): A parent report tool for identifying language delay in toddlers. Fournal of Speech, Language, and Hearing Research 44, 434-45. 
Rescorla, L., Alley, A. \& Book, C. J. (200I). Word frequencies in toddlers' lexicon. Fournal of Speech, Language, and Hearing Research 44(3), 598-609.

Rescorla, L., Ratner, N. B., Jusczyk, P. \& Jusczyk, A. M. (2005). Concurrent validity in the Language Development Survey: Associations with the MacArthur-Bates Communicative Development Inventories: Words and sentences. American Fournal of Speech Language Pathology 14(2), I 56-63.

Slobin, D. I. (1992). Introduction. In The crosslinguistic study of language acquisition, Vol. 3, I-I 3. Hillsdale, NJ : Erlbaum.

Stephany, U. (I997). The acquisition of Greek. In D. I. Slobin (ed.), The crosslinguistic study of language acquisition, Vol. 4, I 83-334. Hillsdale, NJ: Erlbaum.

Tamis-LeMonda, C. S., Bornstein, M. H., Cyphers, L., Toda, S. \& Ogino, M. (I992). Language and play at one year: A comparison of toddlers and mothers in the United States and Japan. International Fournal of Behavioural Development 15, I9-42.

Tardif, T. (1996). Nouns are not always learned before verbs: Evidence from Mandarin speakers' early vocabularies. Developmental Psychology 32, 492-504.

Thomadaki, E. \& Stephany, U. (2007). Diminutives in Greek child language. In I. Savickienè\& U. D. Wolfgang (eds), The acquisition of diminutives, 89-I23. John Benjamin Publishing Company.

Tomasello, M. \& Merriman, E. (eds) 1995. Acquisition of the verb lexicon. New York: Academic Press. 